\title{
Bizans Anonim Follisleri Üzerinde Görülen İslami Kontrmarklar
}

\section{Islamic Countermarks on the Obverse of the Byzantine Anonymous Follises}

\begin{abstract}
Serkan KILIÇ*
Öz: Bu çalışmada kontmark uygulamasının ne zaman ortaya çıktığg ve ne amaçla kullanıldığı, Bizans sikkeleri (Anonim Follisleri) üzerindeki İslami kontrmark çeşitleri hakkında genel bilgilere değinilerek bir öngörüde bulunulmuştur. Bizans anonim follisleri üzerinde yer aldığı tespit edilen 11 adet İslami kontrmark kendi içinde değişik varyasyonlara ayrılmaktadır. Bu çalışmada konu ana hatlarıyla ele alınıp, mevcut araştırmalardaki ilgili verilerin incelenip değerlendirilmesi amaçlanmıştır. Ayrıca katalogda, üzerinde islami kontrmark bulunan Bizans anonim follisleri hakkında detaylı bilgi verilmiştir.
\end{abstract}

Anahtar sözcükler: Bizans, Selçuklu, sikke, anonim follis, damga, İslami kontrmark

Abstract: In this study, a prediction is made as to when and why the use of the countermark occurred, and this is discussed, together with general information concerning the varieties of Islamic countermark struck on Byzantine coinage (anonymous follises). The 11 examples of Islamic countermarks found on the Byzantine anonymous follises are divided into their different variants. The aim of this study was to define the main subject and to analyse and evaluate the related data resulting from the current research. In addition, detailed information is provided in the catalogue of those Byzantine anonymous follises carrying Islamic countermarks.

Keywords: Byzantine, Seljuk, coins, anonymous follis, seal, Islamic countermark

\section{Bizans Anonim Follisleri}

Bizans anonim follisleri (Follis: 40 nummi değerinde bakır sikke), Bizans tarihinin Iustinianus'tan sonraki "ikinci altın çă̆ı" olan İmparator I. Ioannes Tzimiskes (Makedonya Hanedanlığı'nın sekizinci ferdi, M.S. 969-976) döneminde basılmaya başlanmış ve İmparator I. Alexius'un 1092 yılında yaptığı büyük parasal reforma kadar devam etmiştir. Ioannes Tzimiskes adını taşıyan bakır sikke olmaması ve en erken tarihli anonim sikkelerin imparatorlar VII. Konstantinos Porphyrogennetos (M.S. 913-959) ile II. Nikephoros Phokas'ın (M.S. 963-969) bakır sikkelerinin üzerine basılmış olması gibi nümismatik veriler, bu sikkelerin basımının ilk olarak İmparator I. Ioannes Tzimiskes Dönemi’nde başladığını ortaya koymaktadır (Çantay, 2008, 152).

İmparatorluğun bastırdığı bakır anonim follisler, önceki yüzyıllarda basılan sikkelerden iki önemli konuda ayrılmaktadır. Birincisi, bakır sikkeler üzerinde, şimdiye kadar sadece altın sikkeler için tercih edilen bir uygulama olan, İsa'nın bir portresinin yer alması, ikincisi ise sikkelerin herhangi bir imparator adına basılmamış olmasıdır.

İmparator I. Ioannes Tzimiskes, 970'de sikkelerin dizaynını değiş̧irmiş, önyüzdeki imparator portresinin yerine Pantokrator İsa portresini koymuş, arka yüze de "IhSYS XRISTYS

\footnotetext{
* Arş. Gör., Akdeniz Üniversitesi, Edebiyat Fakültesi, Sanat Tarihi Bölümü, Antalya, serkankilic@akdeniz.edu.tr
} 
bASILEY' bASILE" (Kralların Kralı Yüce İsa) lejandını eklemiştir. Tzimiskes'in, farklı şekilde sikke basmasının nedeni olarak, atasının feci bir biçimde öldürülmesinden dolayı duyduğu pişmanlığın bir sonucu olduğu düşünülmektedir. Dönemin haçlı seferleri ve Müslüman savaşları, anonim serisinin başlangıcı için olmasa da devamı için, bilinçli bir dini propaganda amacı taşımasının nedenleri arasındadır (Demirel-Gökalp, 2009, 218-219).

İmparatorluğun, I. Iustinianus'tan sonraki "ikinci altın çağı" olan Makedonya hanedanlığ dönemine ait sikke buluntularındaki artış, askeri, ekonomi, siyasal ve kültürel gelişimin göstergesidir. M.S. XI. yüzyılın ortalarında imparatorluk ordularının büyük bir bölümü Norman, Rus, Türk ve Frank askerlerle, yerli halktan askere alınmış paralı askerlerden oluşmaktaydı. Ordunun hammadde, hazır mal ve erzak ihtiyaçlarının temini için nakde olan gereksinim, Anonim follislerin Anadolu'da çok sayıda bulunmasının muhtemel sebebidir. Ancak M.S. 1050 yılında imparatorluk toprak bakımından genişlemiş olsa da, bu gelişmelerin savunma ve vergi gücünün çökmesi, devletin fakirleşmeye ve askeri gücünü yitirmeye başlaması gibi olumsuz sonuçları vardır. M.S. 1050 yılı sonrasındaki sikke sayısındaki düşüş de bunu desteklemektedir. Bu dönem sikkelerinin sayısı Anadolu'da o kadar çoktur ki, Doğu ve Güneydoğu Anadolu'da İnaloğulları ve Artukoğulları'nın hakim olduğu bölgede, M.S. XI. yüzyıl ve öncesinde basılan ve muhtemelen bu bölgenin fethinden az önce buralarda tedavülde olan Bizans sikkeleri, kontrmarklanmak suretiyle M.S. XII. yüzyılın ikinci yarısında bölgedeki Türk beylikleri tarafindan yeniden tedavüle sokulmuştur (Demirel-Gökalp, 2009, 222-223). Selçuklular döneminde Suriye ve Anadolu'da bulunan M.S. XI. yüzyıla ait follislerde Arap kontrmarkları yaygındır ve sikke sirkülasyonları Anadolu ile Suriye çevresinde ağırlık kazanmıştır (Bellinger, 1973, 97).

\section{Bizans Sikkeleri Üzerinde Görülen İslami Kontrmarklar}

Kontrmark antikçağdan beri bilinen bir uygulamadır. Basılmış olan bir sikkeye sonradan vurulan ufak damgalara verilen ad olan kontrmark, bir harf, kısa bir yazı, bir sayı, insan veya hayvan figürü ya da bir sembol olabilmektedir. Kontrmark uygulaması, eskiyen ya da tedavülden kalkan bir sikkeyi yeniden geçerli kılmak; sikkenin, ait olduğu ya da basıldığı yerin dışında (örneğin başka bir kent ya da ülkede) geçerliliğini sağlamak; değerinde bir değişiklik yapılmak istendiğinde, bu değişikliği belirtmek; metal kalitesinin kontrol edilmiş olduğunu göstermek, ağırlığının doğru ve tam olduğunu belirtmek amacıyla çoğu kültürde kendisine bir yer edinmiştir. En ufak damgalar (Punchmark) Lydia Krallı̆̆g'na atfedilen bazı elektron staterler üzerinde görülmesine rağmen, kontrmarklar esas olarak ancak, M.Ö. IV. yüzyıl ortalarından itibaren görülmeye başlar (Tekin, 1996, 48).

Hellenistik Dönem'de Küçük Asya'da, Büyük İskender'in ölümünden sonra bazı kentler, onun adı ve ikonografisiyle sikkeler darp etmişlerir. Bu sikkelerin bazılarının üzerinde gemi çapası kontrmarkı görülmektedir. Bu esas itibariyle o dönemin güçlü bir siyasi birliği olan Seleukos Krallı̆̆ı'na (M.Ö. IV. yüzyılın son çeyreğinde İskender'in ölümünden sonra haleflerinin kurdukları dört Hellenistik imparatorluktan biridir. Başkentleri önce Seleukeia, sonraları ise Antiokheia olarak belirlenmiştir) aittir. Aynı şekilde Rhodos'un simgelerinden biri olan Helios başı da, sikkeler üzerine kontrmark olarak darp edilmiştir (Tekin, 1994, 24). Anadolu kentlerindeki Roma imparatorluk dönemi sikkelerinde de görülen kontrmark uygulaması, İslam dünyasında da karşımıza çıkmaktadır.

İslami kontrmarklı sikkelerde en sık karşılaşılan Arapça kelimeleri "sadece” - "Allah""güneş ve kişi ismi”nden oluşmaktadır. Buna karşın çoğu kontrmark çözülememektedir. Gürcü kültürüne ait İslami kontrmarklar da M.S. XI. yüzyıl Bizans sikkelerinde yer alabilmektedir (Bellinger, 1973, 98). 


\subsection{Adl}

Sadece ağırlığı belirtmek için kullanılan "adl” kontrmarkının bir diğer yazılışının "dal" olduğu bilinmektedir. Fakat bu bir kontrmark işareti olmaktan ziyade $\mathrm{M}$ ve $\mathrm{N}$ harflerini karşılamaktadır (Fig. 1). Lowick, “Adl” kontrmarkının "doğru ve adil" anlamına geldiğini söylemektedir (Lowick, 1977, 38). Devletin halk üzerinde iyi bir imaj çizebilmesi uygulanan bu kontrmark gayet stratejik bir unsur olarak görülebilir.

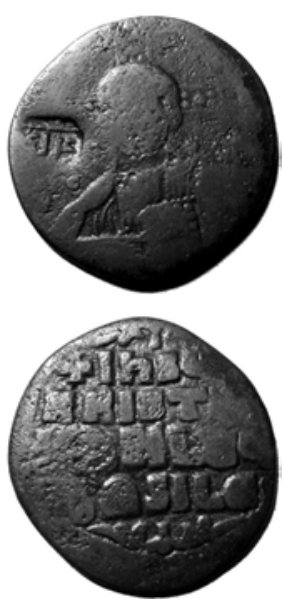

Fig. 1. Adl kontrmarklı Bizans anonim follis

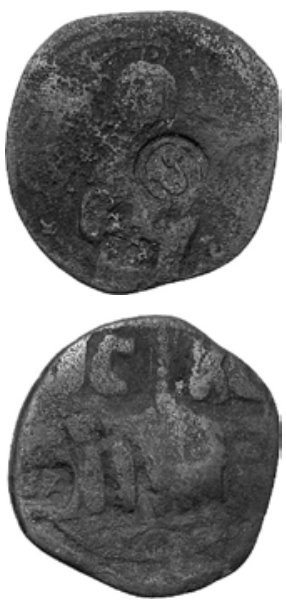

Fig. 2. Izz kontrmarklı Bizans anonim follis

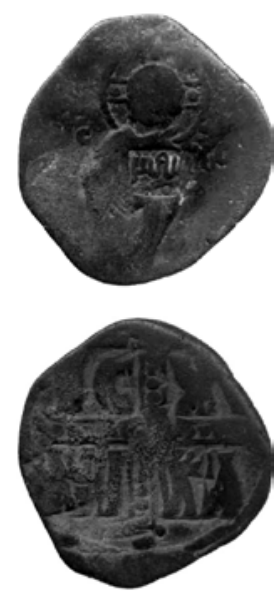

Fig. 3. Shams kontrmarklı Bizans anonim follis

\subsection{Izz}

En çok karşılaştığımız kontrmaklar arasında bulunan "izz”, "şan-ihtişam-zafer" anlamını taşımaktadır. Bu kelime tek başına kullanılabilmesinin yanında genellikle "izz al-din (inancın zaferi)" veya "izz al-dowlah (hanedanlığın ihtişamı)" gibi birden çok kelime ile birlikte de kullanılabilmektedir. Burada "al" yüksek anlamında kullanılmıştır. Böyle kullanılan kontrmarkların 27 adet varyasyonu bulunmaktadır (Fig. 2).

\subsection{Shams}

Genellikle "shams al din (inancın güneşi)" şeklinde kullanılan kontrmarkta "güneş" kelimesi erkek ismine gönderme olarak kabul edilmektedir. 25 farklı versiyonu bulunan bu varyasyonlar harflerin oluşumuna, yıldızların şekline ve yerine göre farklılık göstermektedir. Altta iki yıldız, yanlarda veya ortada nokta olan Shams kontrmarkı, bu kontrmarklar içinde en sık karşılaştı̆̆ımız türlerdir (Fig. 3).

\subsection{Atabeg}

Kurucu, ata, hükümdar anlamına gelen "atabeg” kontrmarkı M.S. XII. yüzyılda özellikle Mezopotamya'da yaşayan Türkmenler ve Kürtler tarafindan yönetici veya atalarını tanıtmak amacıyla kullanılmıştır (Fig. 4).

\subsection{Najm}

"Najm al din (inancın yıldızı-lşı̆̆ı)" anlamında kullanılan kontrmarkın 6 farklı varyasyonu bulunmaktadır. Bu yazıyı genellikle istiridye kabuğunu andıran bir bordür kaplamaktadır. Kufi veya nesih yazısıyla bir kişinin ismi de bu kontrmarkta yer alabilmektedir (Fig. 5). 

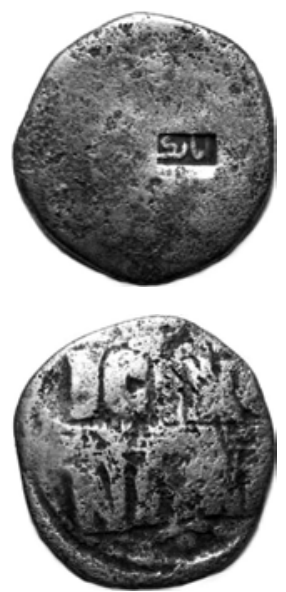

Fig. 4. Atabeg kontrmarklı Bizans anonim follis
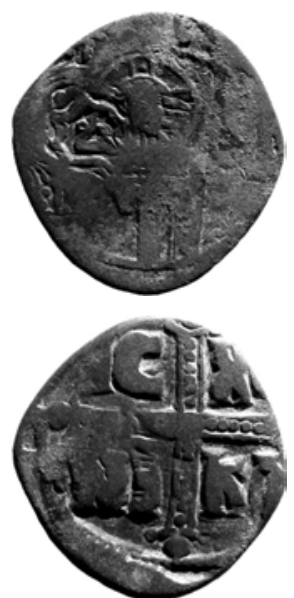

Fig. 5. Najm kontrmarklı Bizans anonim follis

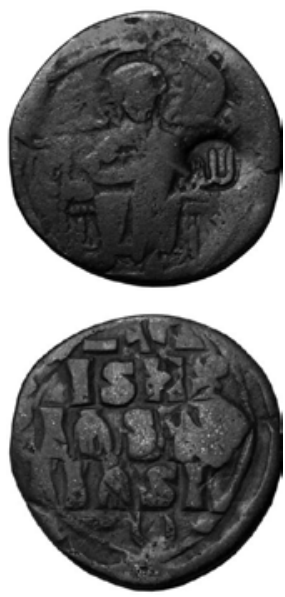

Fig. 6. Lillah (Allah) kontrmarkl1 Bizans anonim follis

\subsection{Lillah (Allah)}

Bizans sikkeleri üzerine en sık darp edilen kontrmark olarak karşımıza çıkmaktadır (Fig. 6). Allah anlamı taşıyan Lillah kontrmarkı kendi içinde karakter olarak 10 gruba ayrılır (Fig. 7). 10 grupta incelenmesi dönemsel farklılıktan kaynaklanmaktadır.

Genel olarak bakıldığında diğer kontrmark çeşitleri 12 grupta incelenmektedir (Fig. 8).

\subsection{Al ghaia}

Sikkeler üzerinde kullanılan onore edici kontrmarklardan ziyade "al ghaia" şeklinde kullanılan kelimeler de mevcuttur, "yüksek kalite" anlamına gelen bu kontrmark, sikkenin metaline ve değerine bir gönderme yapmaktadır.

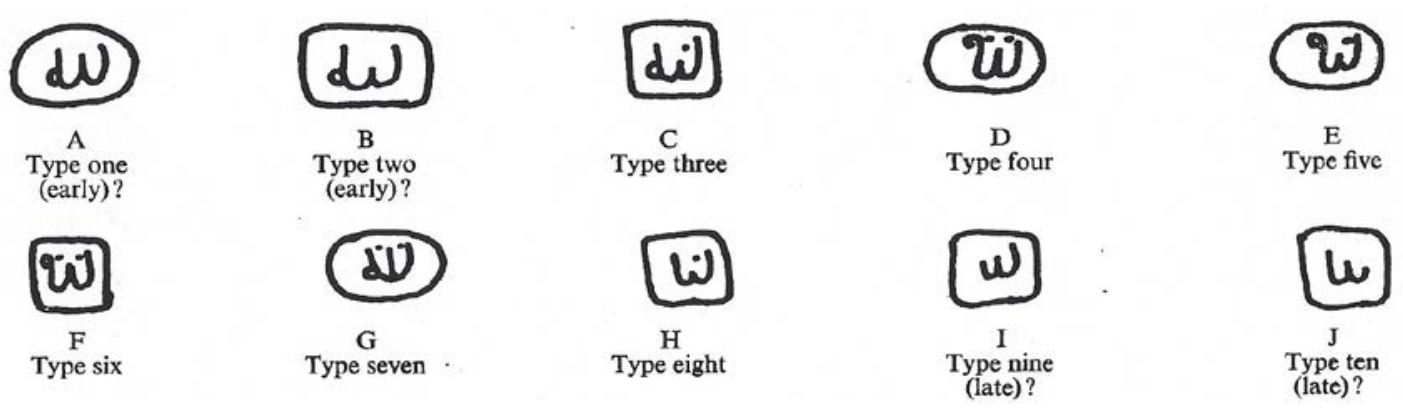

Fig. 7. Lillah Kontrmarkının Varyasyonları (Weller 1975, 477).

\subsection{Saif}

"Saif al din (inancın kılıcl-gücü)" veya "saif al dawlah (hanedanlığın inancl)" anlamında kullanılmaktadır. Kufi veya nesih yazı biçimiyle kullanılan bu kontrmarkın 3 varyasyonu vardır.

\subsection{Mahmud}

İki farklı şekilde yazılan bu kontrmak, kaligrafik özellikler taşımakla beraber "Muhammed" anlamına da gelmektedir.

\subsection{Nür}

"Nür al din (inancın 1şı̆̆ı)" anlamında kullanılan kontrmark, sikkelerde arka ve ön yüzde olmak üzere iki farklı şekilde kullanılmaktadır. 


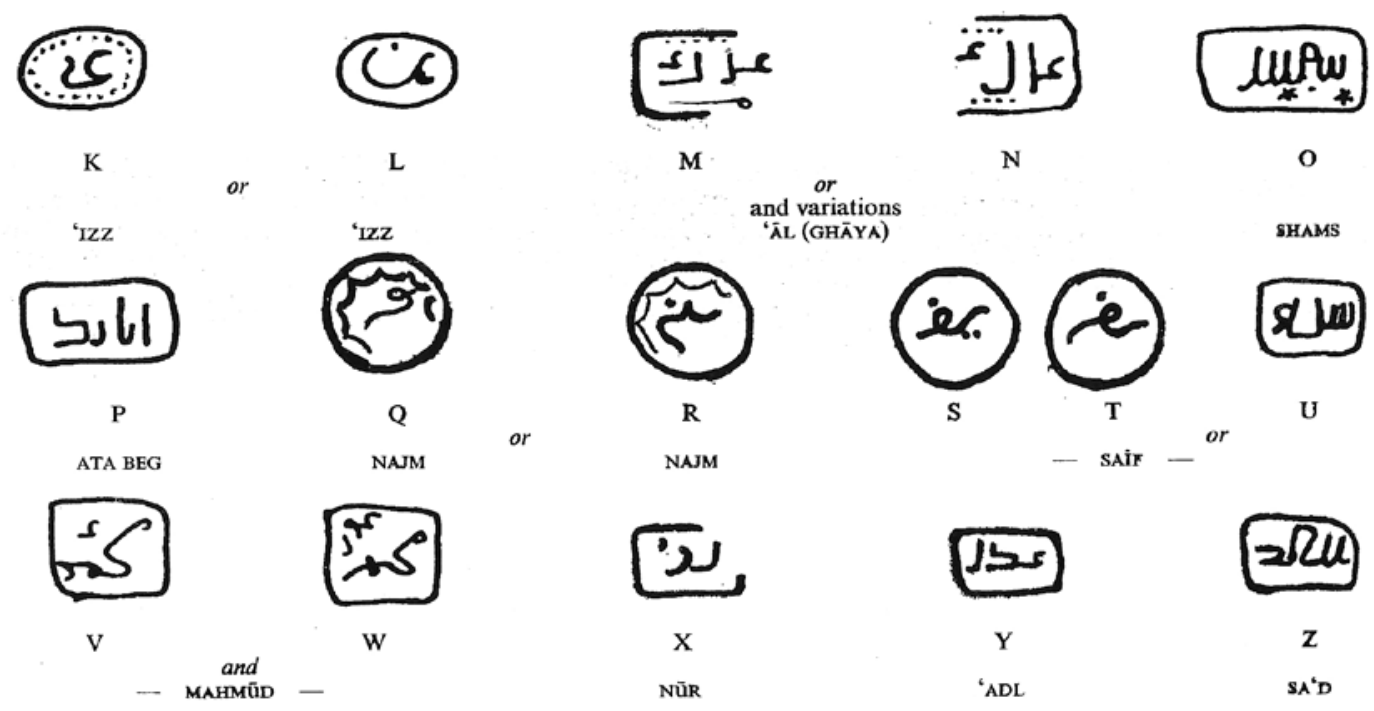

Fig 8. Diğer Kontrmark Çeşitleri (Weller 1975, 477)

\subsection{Sa'd}

Çok az örneği olan bu kontrmark, sikke üzerine basılan bölgenin ana hattını oluşturmaktadır.

Diğer 2 kontrmark ise tam olarak çözülememiş ve tamamlanmamış kontrmarklardır. Türkmenler tarafından kullanılan kontrmarklar, genellikle yarım ve hafif follisler üzerine yapılmaktadır. Bu kontrmarklar, bir sembol veya yazı olabilmektedir (Weller, 1975, 476).

\section{Değerlendirme}

Antikçağdan beri görülen kontrmark uygulaması İslam dünyasında da yer almaktadır. $\mathrm{Bu}$ kontrmarklı sikkelerin dönem içinde ne kadar süre tedavülde kaldığı bilinmemektedir. Bu sebeple Lowick, Bendall ve Whitting, Doğu ve Güneydoğu Anadolu'daki Bizans sikkelerinin, Selçukluların M.S. 1071'deki Malazgirt Zaferi ve Osmanlı'nın kuruluşuna kadar tedavülde kalıp kalmadıklarını araştırmışlardır (Lowick, 1977, 38). Genel olarak bakıldığında M.S. 1071'den sonra bölgede Bizans egemenliği görülmez. Bölgede bir ara egemen olan Haçlılar, Kilikia'daki Armenia Krallığı'nın ve öteki Türk beyliklerinin de kendi sikkelerini bastığı bilinmektedir. Fakat bu toplulukların, kısmen de olsa Bizans sikkelerini kontrmarklamak sureti ile kullanmış olduklarını söylemek doğru olacaktır (Tekin, 1996, 49). Bölgedeki siyasi egemenlik mücadeleleri göz önüne alındığında, Bizans sikkelerine kontrmark vurulduğu dönemin, M.S. 1140/451200 yılları arasındaki dönem olduğu düşünülebilir. Dolayısıyla M.S. XI. yüzyılın Bizans sikkeleri, M.S. XII. yüzyılın ikinci yarısında bölgedeki Türk beylikleri tarafından yeniden tedavüle sokulmuştur. Kuşkusuz bu uygulama, yeni sikke basmaktan daha az masraflı ve daha kolay bir iş olarak görülmüştür. Bizans sikkelerini kullanmaları, bölgedeki Türk beyliklerinin sikke bas1mına geç başlamalarının bir nedeni olarak gösterilmektedir (Tekin 1996, 50). Tekin, kontrmarklama işlevinin Türk beyliklerinin sikke basmaya başlamaları ile ortaya çıktığını, kontrmark işi için ufak da olsa ocak, atölye ve bir görevliye ihtiyaç duyulduğunu ileri sürmektedir. M.S. XII. yüzyıl Anadolu'sunda kontrmarklama, esas olarak aynı zamanda darphane olarak faaliyet gösteren atölyelerde yapılmaktadır (Tekin, 1996, 49-50). 


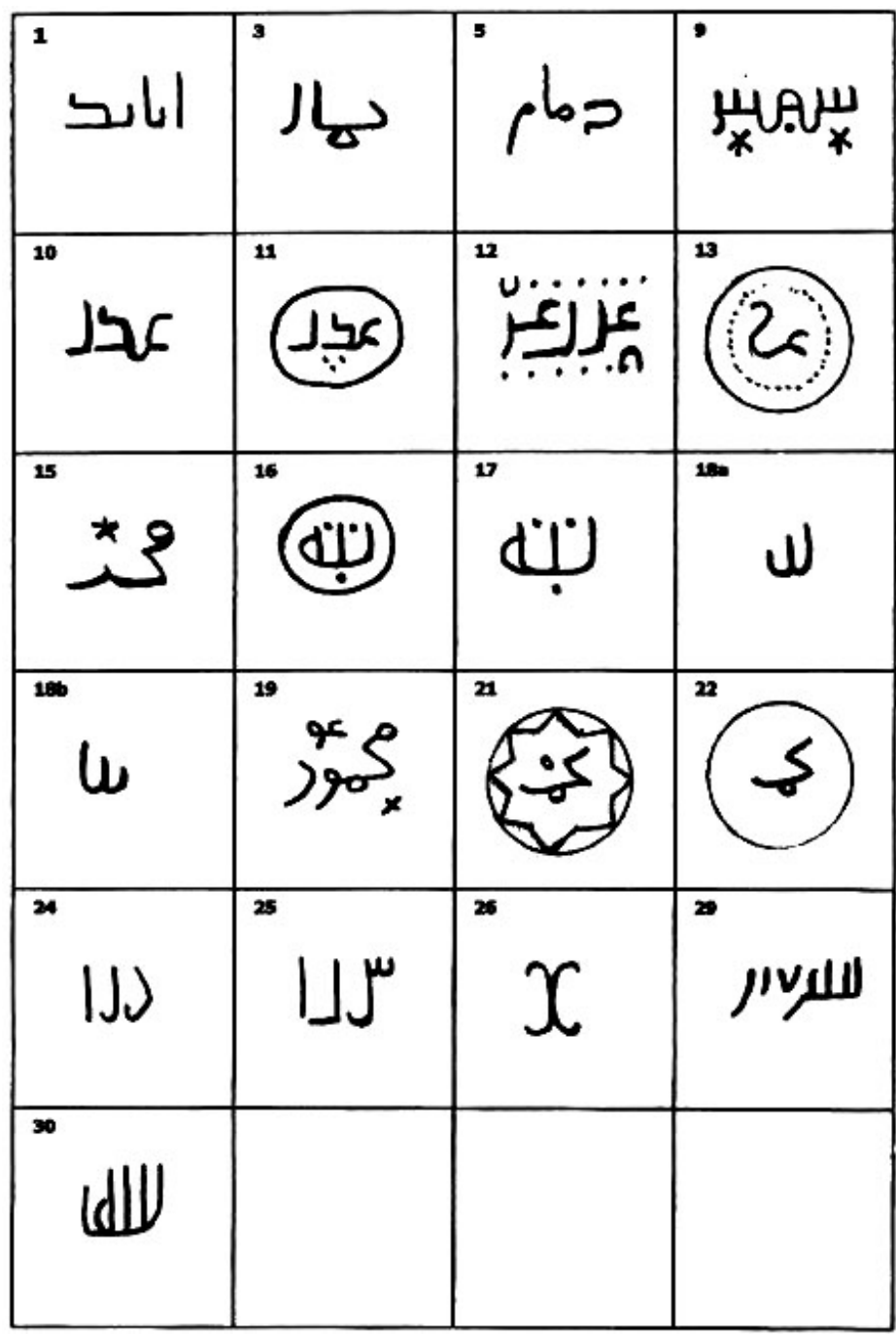

Fig. 9. Bizans Anonim Follisleri Üzerinde Yer Alan Kontrmark Çeşitleri (Goodwin 2005, 328)

Ele geçen definelere bakıldığında (Erzurum definesinden çıkan 153 adet anonim sikkenin 33'ü İslami kontrmarklı olup 1997 yılında Avrupa'da satışa çıkarılmıştır; Bijovsky, \& Berman, 2008, 85), kontrmarklı sikkelerin yanında kontrmarksız olanlar da yer almaktadır. Kontrmarklı sikkelerin vergi (cizye) ödemesi gibi özel amaçlı kullanımı olduğu, kontrmarksız olanların ise günlük alışverişte kullanıldığı düşünülmektedir (Tekin, 1996, 50).

Selçuklu sikkeleri üzerinde damga kullanımı oldukça azdır. Ancak, M.S. XIV. yüzyılın başından itibaren yaklaşık 30 yıl boyunca Karamanoğulları ve Eşrefoğulları'nın hâkimiyet bölgesinde yoğun olarak damga kullanıldığı bilinmektedir. Damgalar, hem mimaride hem de sikkeler üzerinde yazılı, motifli, figürlü olarak yer almıştır. Ancak bu çeşitliliği, Bizans sikkelerinde sadece yazılı olarak görmekteyiz (Perk, \& Öztürk, 2003, 118). Selçuklular döneminde Suriye ve Anadolu'da bulunan M.S. XI. yüzyıla ait follislerde Arap kontrmarkları yaygın olup, sikke sirkülâsyonları Anadolu ve Suriye çevresinde ağırlık kazanmıştır. Bizans sikkeleri, kontrmarklanmak suretiyle M.S. XII. yüzyılın ikinci yarısında bölgedeki Türk beylikleri tarafından yeniden tedavüle sokulmuştur. Kontrmarkların konumuna baktığımızda ise, genellikle sikkelerin ön yüzüne vurulduğunu görmekteyiz (Tekin, 1996, 49).

Bizans ekonomisinde, M.S. VII. yüzyılın sonu ile M.S. VIII. yüzyılda üretim ve takasta köklü 
bir küçülme ve yerelleşme görülmektedir. Bu yerelleşme sonucunda bölgeyi korumak, ordunun genel gereksinimini karşılamak ve askerlerin paralarını ödemek için M.S. XI. yüzyılda nakite ihtiyaç duyulmuştur. Bu yüzden Anadolu'da anonim follislerin sayısı fazladır. Bizans sikkeleri üzerinde toplam 13 çeşit İslami kontrmark bulunmaktadır. Bu sayı, kendi içindeki varyasyonlarıyla birlikte 22'ye ulaşmaktadır (Fig. 9). Bunların başında en çok kullanılan Lillah kontrmarkıdır. Diğer kontrmarklara baktığımızda Izz, Al ghaia, Shams, Atabeg, Najm, Saif, Mahmud, Nür, Adl, Sa'd dışında, diğer iki kontrmark ise tamamlanmamış kontrmarklar sınıfı içinde değerlendirilmektedir. Saydığımız kontrmarklarda genel olarak yücelten, saygı belirten veya dönemin hükümdarına özgü sıfatlar kullanılmıştır.

Bizans anonim follislerinin üzerinde, İslami kontrmark yapılarak oluşturulmuş sikkelerin buluntuları ne yazık ki yetersiz sayıdadır. Anadolu'daki Türk kazılarında çıkan ve müzelerde bulunan malzemeler incelendiğinde İslami kontrmarklı Bizans sikkelerine rastlanmamıştır (İslami kontrmarklı Bizans sikkeleri üzerine derleme yayınlar için bk. Bell, 1921, 297-313; Bayatl1, 1953; Artuk, 1956; Bellinger, 1961; Atlan, 1976; Tekin, 1989, 149-154; Tekin, 1991; Ender, 1994; Özsayg1, 1996, 222; Demirel-Gökalp, 2007; Öğün, 2007; Ünal, 2012a; 2012b; Bayraktar, 2013, 368-377). Ancak, ileride yapılacak kazılardan elde edilecek buluntularla ve müzelerde yürütülecek kapsamlı çalışmalarla bu sikkelerin sayısının atması beklenebilir.

\section{Katalog}

\section{A2 Sinıfi}

(M.S. 976 (?)/ 1030-35) - 1146/1156

1* AE 28/29 mm., 7.39 gr., ky.6

Öy.: + CmmA NOVHA

Cepheden tasvir edilmiş büstünde İsa, sakallı olarak ve varyasyonlara göre her bir kolunda değişik bezemeler yer alan taç nimbus'la görülmektedir. Tunic ve himation giymiş olan İsa, sağ elini takdis pozisyonunda yukarı kaldırmış ve pelerininin kenarından tutar vaziyette, sol eliyle ise İncili tutarken betimlenmiştir. İsa'nın sağında kontrmark darp edilmiştir. Kapakta yine varyasyonlara göre değişiklik gösteren bezemeler yer alır.

Ay.: Dört satır: IhSYS / XRISTYS / bASILEY' / bASILE

Yazının altında ve üzerinde çeşitli süslemeler yer alır (Hangi koleksiyonda yer aldığı bilinmiyor. Detaylı bilgi için bk. http://www.wgs.cc/store/index.php?route=product/product

\&product_id=687), (Fig. 10).

\section{Sinıfi}

Öy.: + CmmA NOVH $\Lambda$

İsa Antiphonetes'in dizlerine kadar betimlenmiş figürü, cepheden sakallı ve haç nimbus'ludur. Haçın her bir kolunda tek nokta bezeme vardır. İsa, tunic ve himation giyimlidir. Sağ elini takdis pozisyonunda yukarı kaldırmış, sol eli ile İncil tutmaktadır. Kapağın içinde nokta bezeme vardır. Sağ ve sol boşlukta IC ve XC. İsa'nın sol vücudunun $3 / 2$ oranına kontrmark darp edilmiştir.

Ay.: Mücevher taşları ile süslü bir haç var. Haçın kollarının ucunda birer nokta, kolları arasında ise IC XC / NI ---

M.S. 1042(?)/1050 - 1146/1183

2* AE 28.1/29 mm., 5.24 gr., ky.6 (Mardin Müzesi koleksiyonunda yer almaktadır. Detaylı 
bilgi için bk. http://www.forumancientcoins.com/catalog/zoompg.asp?param=36226q00.jpg

\&idd=47047\&fld=http://www.forumancientcoins.com/Coins2/)

Ref.: DOC 3/2, s. 681, no.C.2

3* AE 28/26 mm., 6.7 gr., ky.6 (Fitz William Müzesi koleksiyonunda yer almaktadır. Detaylı bilgi için bk. http://www.fitzmuseum.cam.ac.uk/opac/search/cataloguesummary.html? _ searchstring_=\%28object_name=\%27follis\%27\%20and\%20administration_name=\%27Coins $\%$ 20and\%20Medals\%27\%29\&_limit_=50\&_function_=xslt\&_resultstylesheet_=imagecs).

4* AE 26/28 mm., 6.5 gr., ky.6 (Mardin Müzesi koleksiyonunda yer almaktadır. Detaylı bilgi için bk. http://www.coins2.com/imgsearch/islamic\%20countermark/)

5* AE 28/29 mm., 6.00 gr., ky.6 (Mardin Müzesi koleksiyonunda yer almaktadır). Ayrıca bk. http://www.vcoins.com/en/stores/tom_vossen/165/product/artuqids_najm_aldin_alpi_

$12^{\text {th }}$ ccentury_ad_islamic_countermark_mardin_type_21_on_anonymous_follis_class_a_600_g m_29mm/287428/Default.aspx)

\section{Sinıfı}

Öy.: Yazı yok, İsa kare arkalıklı bir tahtta oturuyor, cepheden ve sakallı olarak görülmektedir. Haç nimbuslu, haçın her bir kolunda birer nokta bezeme vardır. Tunic ve himation'lu, sağ eli takdis pozisyonunda göğsündedir. Sol eli dizindeki kitapta? Kitabın üzerine Lillah kontrmark1 darp edilmiştir.

Ay.: Üç sıra : ISXS / bASI-- / bASIL, yazının üzerinde; _+

Yazının altında;

M.S. 1050/1060

6* AE 29/28 mm., 5.4 gr., ky.6 (Mardin Müzesi koleksiyonunda yer almaktadır. Ayrıca bk. http://www.vcoins.com/en/stores/tom_vossen/165/product/artuqids_najm_aldin_alpi_12 $2^{\text {th }}$ cent ury_ad_islamic_countermark_mardin_type_21_on_anonymous_follis_class_a_600_gm_29mm/ 287428/Default.aspx)

Ref.: DOC 3/2, s. 685, no.D.1 


\section{Motifs on Anonymous Folles, Class A2}

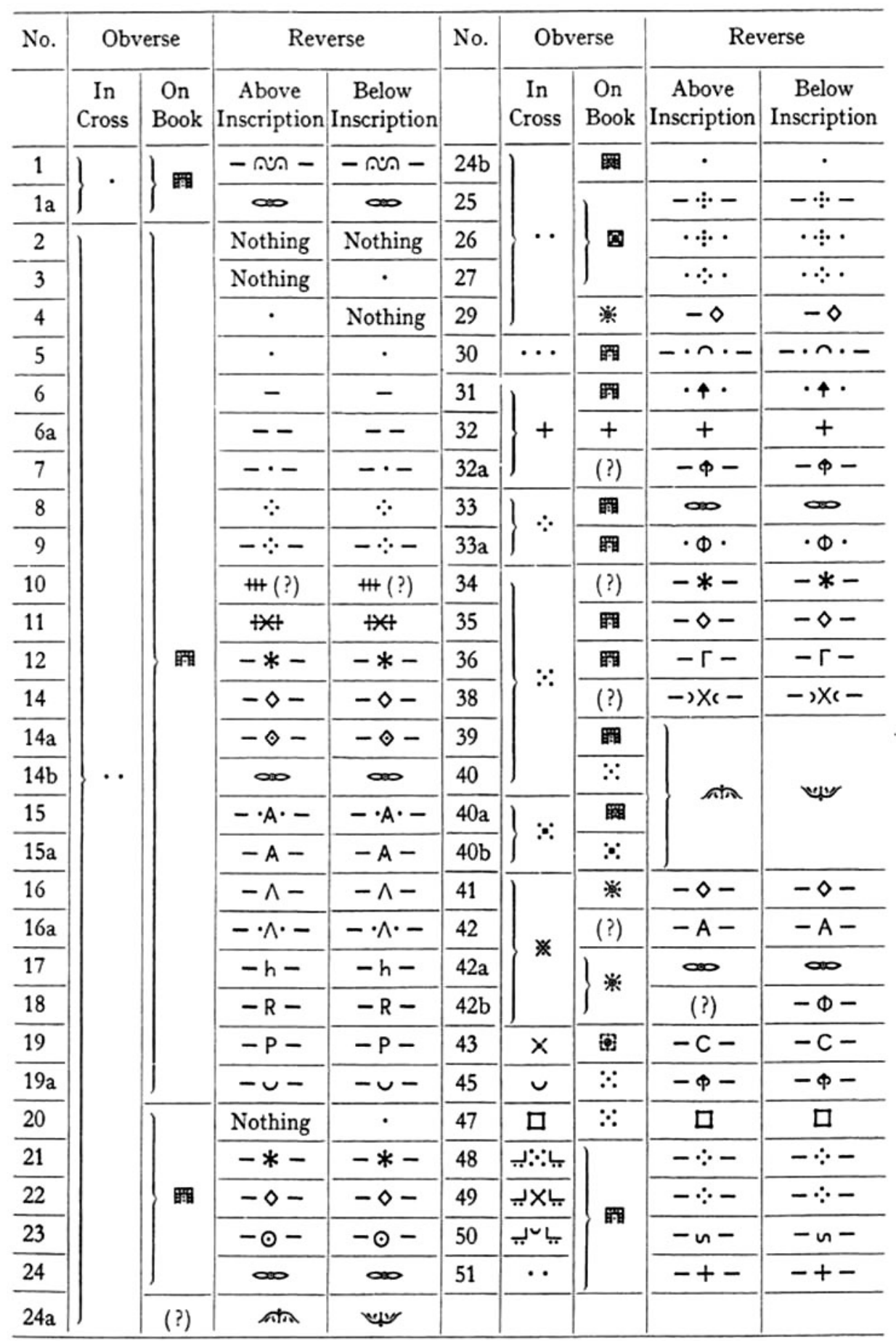

Fig. 10. Anonim A2 Üzerinde Yer Alan Motifler (Grierson 1973, 645). 


\section{KAYNAKÇA}

Artuk, C. (1956). Koleksiyonumuzdaki Nicaea (İznik) Sikkeleri. İstanbul: Çituri Biraderler Basımevi.

Atlan, S. (1976). “1947-1967 yılları Side Kazıları Sırasında Elde Edilen Sikkeler”. TTK Yayınları, V. Dizi, Sayı 34. Antalya Bölgesinde Araştırmalar, 9, Ankara.

Bayatlı, O. (1953). Bergama Tarihinde Sikkeler. Bergamayı Sevenler Cemiyeti Yayımı: IX

Bayraktar, H. (2013). “2012 yılı Psidia Antiokheia Kazısı Sikkeleri: Ön Rapor”. Pisidia Araştırmaları I, Sempozyum Bildiri Kitabl, 368-377. Eds.: B. Hürmüzlü, M. Fırat, A. Gerçek. Isparta.

Bellinger, R. A., \& Grierson P. (Ed.). (1973 ). "Leo III to Nicephorus III 717-1081”. Catalogue of the Byzantine Coins in the Dumbarton Oaks Collection and in the Whittemore Collection, 3/1. Dumbarton Oaks Center for Byzantine Studies, 97. Washington, D.C,

Bellinger, R. A. (1961). Troy The Coins, Supplementary Monograph 2. Princeton University Press for University of Cincinnati.

Bell, H. W. (1921). “Coins from Assos”. Excavations at Assos, 297-313. Ed.: T. J. larke, T. F. H. Bacon, R. Koldewey. London-Leipzig, Massachusetts.

Bijovsky, G., \& Berman, A. (2008). "Tiberias Excavations in the House of the Bronzes”. Final Report, I/3, Architecture, Stratigraphy and Small Finds (Qedem 48). Monographs of the Institute of Archaeology, 85. The Hebrew University of Jerusalem, Jerusalem.

Çantay, D. (2008). Edirne Makedonya Kulesi Kurtarma Kazllarında Ele Geçen Bizans Sikkeleri ve Mühürleri. Yayımlanmamış Yüksek Lisans Tezi. Hacettepe Üniversitesi, Sosyal Bilimler Enstitüsü, Sanat Tarihi Anabilim Dalı, Ankara.

Demirel-Gökalp, Z. (2007). Yalvaç ve Isparta Arkeoloji Müzelerinde Bulunan Bizans Sikkeleri. Yayınlanmamış Yüksek Lisans Tezi. Anadolu Üniversitesi, Eskişehir.

Demirel-Gökalp, Z. (2009). “Malatya Arkeoloji Müzesi’nde Bulunan Anonim Follisleri”. Anadolu Üniversitesi Sosyal Bilimler Dergisi, 9/1, 218-219.

Ender, C. (1994). “Ladik (Denizli) Sikkeleri”. Nümismatik Yayınları,1. İstanbul.

Grierson, P. (1973). "Leo II to Nicephoros II 717-1081”. Eds.: A. R. Bellinge, P. Grierson. Catalogue of the Byzantine Coins in the Dumbarton Oaks Collection and the Whittemore Collection, 3/1-2, 645. Washington, D. C.

Goodwin, T. (2005). "A Hoard of Tenth and Eleventh Century Byzantine Folles with Arabic Countermarks”. Numismatic Circular, 321-339.

Lowick, N. M., Bendall S., \& Whitting P. D. (1977). “The Mardin' Hoard, İslamic Countermarks on Byzantine Folles”. A. H. Baldwin, Sons Ltd., Hampshire, 38.

Öğün-Çizmeli, Z. (2007). "Kaunos Kentinin Bizans Dönemi Sikke Buluntuları (1965-2002)”. Baki Öğ̈ün'e Armağan. Eds. C. Işı1k, Z. Ç. Öğün, B. Varkıvanç. Ankara: TTK Yayınları.

Özsaygı, M. (1996). "Yeni Bulunan Bir Aspendos Definesi”. Arkeoloji Dergisi, IV, 222. Ege Üniversitesi Edebiyat Fakültesi, İzmir.

Perk, H., \& Öztürk, H. (2003). "XIV. Yüzyılın İlk Yarsında Anadolu'daki İslam Paraları Üzerinde Görülen Bir Kısım Damgalar". VII. Ortaçağ ve Türk Dönemi Kazı ve Sanat Tarihi Araştırmaları Sempozyumu Bildirileri (7-8-9 Nisan 2003), 118-119. Mimar Sinan Güzel Sanatlar Üniversitesi, Fen Edebiyat Fakültesi, Sanat Tarihi Bölümü.

Tekin, O. (1989). "Perge Kazılarında Bulunan Sikkeler Hakkında Ön Rapor". Anadolu Araştırmaları, Sayı XI, 149-154. Edebiyat Fakültesi Basımevi, İstanbul.

Tekin, O. (1991). Aspendos Sikkeleri. Yayımlanmamış Yüksek Lisans Tezi. İstanbul.

Tekin, O. (1994). Grek ve Roma Sikkeleri. Yapı Kredi Koleksiyonu, 24. İstanbul.

Tekin, O. (1996). “Aşağı Anzaf (Van) Kazısından İslami Kontrmarklı Bir Bizans Sikkesi”. Toplumsal Tarih, Aralık/36, 48.

Ünal, C. (2012). İzmir İli ve İlçeleri (Bergama, Efes, Ödemiş Müzeleri) Örnekleri ile I. Dönem Bizans Sikkeleri, 5. Yüzyıl Sonu-8. Yüzyll Ortası. Manisa.

Ünal, C. (2012). Manisa Müzesi Bizans Sikkeleri. Manisa: Celal Bayar Üniversitesi Yayınları. 
Weller, H. (1975). “Turkic Countermarks”. The Numismatic Circular, Vol. LXXXIII, 476.

\section{İnternet Kaynakları}

http://www.wgs.cc/store/index.php?route=product/product\&product_id=687 (14.06.2013).

http://www.forumancientcoins.com/catalog/zoompg.asp?param=36226q00.jpg\&idd=47047\&fld=http://w ww.forumancientcoins.com/Coins2/ (07.06.2011) .

http://www.fitzmuseum.cam.ac.uk/opac/search/cataloguesummary.html?_searchstring_=\%28object_name $=\% 27$ follis\%27\%20and\%20administration_name $=\% 27$ Coins\%20and\%20Medals\%27\%29\&_limit_= 50\&_function_=xslt\&_resultstylesheet_=imagecs (07.06.2011).

http://www.coins2.com/imgsearch/islamic\%20countermark/ (07.06.2011).

http://www.vcoins.com/en/stores/tom_vossen/165/product/artuqids_najm_aldin_alpi_12th_centery_ad_i slamic_countermark_mardin_type_21_on_anonymous_follis_class_a_600_gm_29mm/287428/Defau lt.aspx (13.06.2013).

http://www.forumancientcoins.com/gallery/displayimage.php?album=3405\&pos=5 (13.06.2013). 